\title{
Constraints Lead to Opportunities for Medical Education in Times of COVID-19 Pandemic
}

\author{
Os Constrangimentos Conduzem a Oportunidades para \\ a Educação Médica em Tempos de Pandemia COVID-19
}

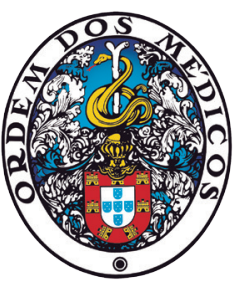

João Carlos RIBEIRO 1,2 , Tiago VILLANUEVA², Andreia GI $\rrbracket^{1,2}$, Pedro ESCADA ${ }^{2,3}$

Acta Med Port 2020 Oct;33(10):638-639 - https://doi.org/10.20344/amp.14040

Keywords: COVID-19; Education, Medical; Pandemics; Portugal; Students, Medical

Palavras-chave: COVID-19; Educação Médica; Estudantes de Medicina; Pandemia; Portugal

The COVID-19 pandemic poses significant health constraints to us both as individuals and as a community. Medical schools deal with that at a student, faculty and society level. Both students and faculty are dealing with enormous changes that may be relatively small in comparison to the global pandemic chaos but have the potential to be an enormous turning point in medical education, the future of medicine and consequently in society care sooner or later.

\section{Constraints}

Social confinement minimizes the level of personal interactions and consequently of student to patient exposure. It is required in order to protect students from exposure given the widespread lack of personal protective equipment (PPE). But it is acknowledged that there will be a negative impact on medical student learning opportunities ${ }^{1}$ because of shortening the length of clerkships and hindering collaborative experience, skills acquisition and development of relationships with patients.

\section{What are medical schools doing?}

Medical schools promptly embraced the challenge and tried to adapt as efficiently as possible, through the implementation of a distance learning system. This shift from on-campus teaching and 'real life' clinical experiences to a distance learning model raised doubts and concerns that were quickly mitigated by students' engagement to online classes in real time and pre-recorded lectures. The ability of self-directed learning is now being developed since, unlike before, faculty now provides additional studying material and study time. Moreover, class interaction, integration of theoretical knowledge and the practice of reflection on learning experiences have improved with the use of interactive clinical cases. ${ }^{2}$ These strategies are important to prepare students for the National Medical Licensing examination, but also to value educational methods used to achieve affective learning objectives and to increment self-direct learning.

The implementation of virtual patient cases is helping to develop clinical reasoning skills but makes it harder for students to develop physical examination skills, and this will be one of the greatest difficulties that students from the clinical years will face. ${ }^{3}$

Even with online classes, not all in-person course units can be replaced by digital tools. It Is widely recognized that, on its own, providing formal knowledge is not enough to train a clinical expert. Medical education explicitly involves coordination of both analytical and experiential knowledge. ${ }^{4}$

Another problematic issue is the uncertainty surrounding assessment methods. Continuous practical assessment, the basis for medical students' assessment in clinical rotations cannot be done anymore. Some faculties planned a range of online solutions that are very difficult to implement in classes with 400 students. Furthermore, there have been internet connection problems, which may not be easy to solve or predict. Technology is advancing, but it is not flawless. ${ }^{5}$

We all think of this though times as difficult ones. And they are. But we can also think of them as opportunities do evolve. We aim at showing some different opportunities that may lead to an evolution in the medical education.

\section{Opportunities}

Medical students usually operate both as providers and shadowers. As shadowers, the contact time is very important. Constraints in social contact will lead to the ratio of contact versus non-contact hours decreasing. Because we must maintain (and if possible, improve) the quality of undergraduate medical training, we must seek new ways of learning and teaching. Schools restricted their degree of student involvement not only with COVID-19 patients but with all kinds of patients as well. With the progression of the epidemic curves, their controlled involvement could make future medical doctors more accountable.

There are substantial differences in terms of clinical contact restrictions depending at what stage students are in. In pre-clinical years, virtual lectures can be seen as an asset as long as they enhance teaching by visual means

1. Faculdade de Medicina. Universidade de Coimbra. Coimbra. Portugal.

2. Acta Medica Portuguesa. Lisboa. Portugal.

3. NOVA Medical School. Lisboa. Portugal.

$\triangle$ Autor correspondente: Andreia Gi. andreiagi@outlook.pt

Recebido: 04 de maio de 2020 - Aceite: 29 de junho de 2020 | Copyright $\odot$ Ordem dos Médicos 2020 
(for example, 3D human anatomy and physiology online atlas, virtual histology laboratories and interactive e-learning tools). In clinical years, virtual interactive patient platforms are useful since medical students can put knowledge into practice and test clinical reasoning and medical decision through realistic cases. ${ }^{6}$

We are tending now towards asynchronous learning 'anytime/anywhere', where there are no time or synchronous place limitations. Although some reality features and uncertainties may not be reached, the general medical mainstream way of thinking may be more easily achieved with asynchronous clinical models. ${ }^{7}$

Moreover, traditional educational methods are accepted and replicated from tutors to students that will teach in the same way in the future. They are certainly well accepted methods of teaching, but last year's increase in numerus clausus, and the consequence of the social restraints of the more recent pandemia must compel us to try out and evaluate different educational strategies and methods using medical education research methods. And we can go further with the opportunities that recent haptic technologies, with visual, sensorial and simulation capabilities, deliver. Using websites and analyzing databases with statistical software improves student confidence and teaching results. Gamification and multimedia play a very important role in students already presenting a high technological literacy level.

With many recent educational experiences with good outcomes, some pre-clinical classes may tend to be permanently scheduled by online asynchronous methods. This would liberate physical spaces to other classes, with a consequent lower student/ area ratio. Depending on the subject, medical students do not always require active teaching. Even exams could end up being deployed through digital systems, not only with traditional multiple questions but also with interactive questions based on previous answers or by gamification processes.

Traditional education tend to focus heavily on academic knowledge, at the cost of overlooking clinical reasoning and social involvement skills. We may start evaluating what really matters, with patient simulation, where every choice influences the patient's reaction. That might have greater long-term value than a more theoretical exam. Besides, in medicine, soft skills are essential to success and this pandemic is testing and developing students' communication, adaptability, empathy and proactivity skills. We have now an excuse to review educational programs more extensively.

Medical students also operate as providers. The knowledge of $6^{\text {th }}$ year students in health care is quite substantial and useful to society. Well trained medical students provide extra hands that are certainly worthwhile during this outbreak, not only in COVID (e.g. screen and triage, patient follow-up at home), but also in non-COVID areas (e.g. infection prevention in households or children nurseries during medical professional's worktime) are equally important. At the same time, they can gain clinical and social experience. It is a unique opportunity to gain experience in epidemiology, infectious diseases or intensive care. We may use these ideas both in the current pandemic times and future events. Additionally, this kind of work can be part of their formal training and help pay the university tuition fees. Nevertheless, we must be cautious. Although medical students are prepared to recognize disease processes and to propose the best treatment for most common illnesses, they lack clinical experience and are not trained on how to work in a health system that is changing and adapting every day.

In conclusion, we are confident that persistence and adaptability skills will increase in medical schools as a consequence of the COVID-19 pandemic. It is not a temporary change, but rather a future wider change in medical education.

\section{REFERENCES}

1. Rose S. Medical student education in the time of COVID-19. JAMA. 2020;323:2131-2.

2. Young JE, Williamson MI, Egan TG. Students' reflections on the relationships between safe learning environments, learning challenge and positive experiences of learning in a simulated GP clinic. Adv Health Sci Educ Theory Pract. 2016;21:63-77.

3. Kononowicz AA, Woodham LA, Edelbring S, Stathakarou N, Davies $D$, Saxena $N$, et al. Virtual patient simulations in health professions education: systematic review and meta-analysis by the digital health education collaboration. J Med Internet Res. 2019;21:e14676.

4. Richmond A, Cooper N, Gay S, Atiomo W, Patel R. The student is key: a realist review of educational interventions to develop analytical and

non-analytical clinical reasoning ability. Med Educ. 2020 (in press). doi: 10.1111/medu.14137.

5. Pickering JD, Swinnerton, BJ. Exploring the dimensions of medical student engagement with technology-enhanced learning resources and assessing the impact on assessment outcomes. Anat Sci Educ. 2019;12:117-28.

6. Stepan K, Zeiger J, Hanchuk S, Del Signore A, Shrivastava R, Govindaraj $\mathrm{S}$, et al. Immersive virtual reality as a teaching tool for neuroanatomy. Int Forum Allergy Rhinol. 2017;7:1006-13.

7. Villatoro $\mathrm{T}$, Lackritz $\mathrm{K}$, Chan JS. Case-based asynchronous interactive modules in undergraduate medical education. Acad Pathol. 2019;6:2374289519884715. 